\title{
Beer makes the heart grow fonder; single-target implicit attitudes toward beer but not alcohol are related tot drinking behaviour in regular beer drinkers
}

Citation for published version (APA):

Houben, K. M. P. I., \& Wiers, R. W. H. J. (2009). Beer makes the heart grow fonder; single-target implicit attitudes toward beer but not alcohol are related tot drinking behaviour in regular beer drinkers. Netherlands Journal of Psychology, 65(1), 10-21. https://doi.org/10.1007/BF03080123

Document status and date:

Published: 01/01/2009

DOI:

10.1007/BF03080123

Document Version:

Publisher's PDF, also known as Version of record

Document license:

Taverne

Please check the document version of this publication:

- A submitted manuscript is the version of the article upon submission and before peer-review. There can be important differences between the submitted version and the official published version of record.

People interested in the research are advised to contact the author for the final version of the publication, or visit the DOI to the publisher's website.

- The final author version and the galley proof are versions of the publication after peer review.

- The final published version features the final layout of the paper including the volume, issue and page numbers.

Link to publication

\footnotetext{
General rights rights.

- You may freely distribute the URL identifying the publication in the public portal. please follow below link for the End User Agreement:

www.umlib.nl/taverne-license

Take down policy

If you believe that this document breaches copyright please contact us at:

repository@maastrichtuniversity.nl

providing details and we will investigate your claim.
}

Copyright and moral rights for the publications made accessible in the public portal are retained by the authors and/or other copyright owners and it is a condition of accessing publications that users recognise and abide by the legal requirements associated with these

- Users may download and print one copy of any publication from the public portal for the purpose of private study or research.

- You may not further distribute the material or use it for any profit-making activity or commercial gain

If the publication is distributed under the terms of Article 25fa of the Dutch Copyright Act, indicated by the "Taverne" license above, 


\section{Beer makes the heart grow fonder: single-target implicit attitudes toward beer but not alcohol are related to drinking behaviour in regular beer drinkers}

Katrijn Houben* and Reinout W. Wiers**

Previous studies demonstrated that positive implicit attitudes toward alcohol, assessed with unipolar Implicit Association Tests (IATs), are related to drinking behaviour while negative implicit alcohol attitudes are not. However, because the IAT is a relative measure, the present study aimed at replicating these findings with non-relative unipolar Single Target-IATs (STIATs). Further, participants performed ST-IATs with either alcohol or beer as the target concept. Because we only included regular beer drinkers in this study, it was expected that scores on the beer ST-IAT would be more strongly related to drinking behaviour than scores on the alcohol ST-IAT. Consistent with previous findings, both alcohol and beer ST-IATs supported the coexistence of positive and negative implicit alcohol-related attitudes. Further, correlational analyses showed that positive implicit attitudes toward beer were related to drinking behaviour, while negative implicit attitudes were not. Implicit attitudes toward alcohol, in contrast, were unrelated to drinking behaviour. Hence, these findings suggest that the beer ST-IAT assessed more behaviour-relevant implicit attitudes compared with the alcohol ST-IAT. Implications and limitations of these results are discussed and suggestions for future research are given in the discussion. (Netherlands Journal of Psychology, 65, 10-21.)

Keywords: alcohol; implicit attitudes; Implicit Association Test

The past decade, there has been a surge of interest in implicit attitudes in many areas of psychological research, including research on the aetiol-

\footnotetext{
* Maastricht University

** Maastricht University, Behavioural Science Institute, Radboud University, Nijmegen and IVO Addiction Research Institute Rotterdam

Correspondence to: Katrijn Houben, Clinical Psychological Science, Maastricht University, PO Box 616, NL 6200 MD Maastricht,e-mail:K.Houben@psychology.unimaas.nl Submitted 28 July 2008; revision accepted 5 January 2009.
}

ogy and maintenance of addictive behaviours. This interest was fuelled by the advent of indirect measures such as the Implicit Association Test (IAT; Greenwald, McGhee, \& Schwartz, 1998) which, unlike direct self-report measures, do not depend on participants' willingness and ability to introspect and report the reasons for their behaviour, and which may even assess implicit cognitions that influence behaviour outside conscious awareness (e.g. Gawronski, Hofmann, \& Wilbur, 2006). The IAT, for instance, is a speeded classification task that infers implicit 
attitudes from the simultaneous classification of two target categories (e.g., flowers vs. insects) and two evaluative attribute categories (e.g., positive vs. negative). The IAT rests on the assumption that simultaneously classifying target concepts and attribute categories should be easier when associated categories share a response (e.g., flowers + positive vs. insects + negative) than when unassociated categories are mapped onto the same response (e.g., flowers + negative vs. insects + positive). Hence, the performance difference between these two combination tasks is assumed to reflect the strength of implicit attitudes toward the target concepts.

Using the IAT as a measure of implicit alcoholrelated cognitive processes, Wiers, van Woerden, Smulders, and de Jong (2002) showed that both light and heavy drinkers more easily paired alcohol with negative attributes than with positive attributes, suggesting that both light and heavy drinkers have negative implicit attitudes toward alcohol. Wiers et al., however, did find a differentiation between light and heavy drinkers in the arousal dimension with the IAT and, therefore, suggested that implicit arousal associations with alcohol might be more strongly related to drinking behaviour than implicit attitudes toward alcohol (e.g., De Houwer, Crombez, Koster, \& De Beul, 2004; Wiers, van de Luitgaarden, van den Wildenberg, \& Smulders, 2005). There are, however, two methodological problems of the IAT which may preclude this interpretation. First, the IAT is not well suited to measure implicit attitudes towards attitude objects for which ambivalence may exist, due to the bipolarity of the attribute dimension (e.g. positive vs. negative). Since attitudes toward alcohol have been demonstrated to be highly ambivalent (Conner \& Sparks, 2002), this methodological limitation of the IAT may have prevented these earlier studies from finding a strong relationship between implicit alcohol attitudes and drinking behaviour. Second, the IAT is intrinsically a relative measure because it compares implicit associations of one target concept (e.g., alcohol) with those of a second target concept (e.g., soft drinks) (e.g., De Houwer, 2002; Karpinski \& Steinman, 2006; Wigboldus, Holland, \& van Knippenberg, 2004). Therefore, findings with the IAT do not necessarily reflect implicit attitudes toward alcohol, but can also reflect implicit soft drink-related attitudes or a combination of both. Thus, the possibility exists that previous studies that did not demonstrate a strong relationship between IAT scores and drinking behaviour, failed to do so because the IAT scores reflected implicit attitudes toward soft drinks rather than toward alcohol.

In response to these methodological limitations of the IAT, implicit attitudes toward alcohol were recently assessed using IATs with unipolar attribute dimensions (e.g., positive vs. neutral).
Using such unipolar IATs, it was demonstrated that performance was faster when alcohol was paired with positive attributes than when alcohol and neutral attributes shared a response, and also that performance was faster when alcohol was paired with negative attributes than when alcohol was paired with neutral attributes. More importantly, a relationship was demonstrated between positive implicit attitudes toward alcohol and alcohol consumption whereas negative implicit attitudes toward alcohol were not related to alcohol use (Houben \& Wiers, 2006; Jajodia \& Earleywine, 2003; McCarthy \& Thompsen, 2006). Hence, these results suggest that positive implicit attitudes toward alcohol may play an important role in drinking behaviour while negative implicit attitudes toward alcohol appear to be irrelevant to drinking behaviour. However, it is important to note that the unipolar IAT is still intrinsically relative and therefore results can not be interpreted in isolation of implicit attitudes towards the contrast category (e.g., soft drinks). Houben and Wiers (2006) addressed this issue and demonstrated both negative and positive implicit attitudes toward alcohol regardless of whether the target category alcohol was contrasted with the category soft drinks or a category consisting of neutral animals in the IAT. However, although exemplars of the animals category were overall evaluated as neutral, positive implicit attitudes with respect to the category 'animals' could still have influenced IAT performance. Hence, while comparing IAT results with different contrast categories can be useful, using the IAT to assess implicit attitudes regarding single target concepts that are not part of a natural dichotomy remains problematic.

To address this issue, we used a non-relative variant of the IAT, the Single-Target IAT (ST-IAT; Wigboldus et al., 2004; see also Karpinski \& Steinman, 2006), to assess single (i.e., nonrelative) implicit attitudes toward alcohol. The ST-IAT is structurally similar to the IAT with the difference that only one target category is presented during the task. Therefore, unlike the IAT, the ST-IAT measures implicit attitudes toward single target concepts. At this point, it should be noted that other non-relative indirect measures have been developed, such as affective priming and the Extrinsic Affective Simon Task (EAST; De Houwer, 2003). Moreover, de Jong, Wiers, van de Braak, and Huijding (2007) have already used the EAST to examine single implicit alcohol-related attitudes and were able to demonstrate positive implicit attitudes toward soft drinks and neutral or ambivalent implicit attitudes toward alcohol in both light and heavy drinkers. De Jong et al. also demonstrated that positive implicit alcohol attitudes predicted drinking behaviour, which is consistent with findings with unipolar IATs (e.g., Houben \& Wiers, 2006). One caveat, however, is that these 
indirect measures are unsuited to test positive and negative implicit attitudes separately. For this reason, we opted for the ST-IAT in the present study, which we presented in a unipolar format. In similar vein, the EAST has been modified for this purpose, however, at the expense of losing its non-relative nature with respect to the target categories (Wiers, Ganushchack, Van de Ende, Smulders, \& de Jong, 2003). For now, it remains unclear whether these indirect measures can be modified so they are not only nonrelative with respect to the targets, but also unipolar with respect to the attributes.

Thus, in the present study, we examined whether results with unipolar ST-IATs would also demonstrate a relationship between positive implicit alcohol attitudes and drinking behaviour but not between negative implicit alcohol attitudes and behaviour, as was previously found using unipolar IATs. In addition, previous findings with the unipolar IAT suggest that positive implicit attitudes toward alcohol are related to actual drinking behaviour while negative implicit attitudes toward alcohol are not (e.g., Houben \& Wiers, 2006; Jajodia \& Earleywine, 2003; McCarthy \& Thompsen, 2006). Thus, while the positive unipolar IAT variants appear to capture behaviour-relevant implicit attitudes toward alcohol, the negative unipolar IAT variants do not. One explanation for this finding is that negative implicit alcohol-related attitudes do not influence behaviour (perhaps until some threshold is reached as was found for explicit alcohol-related cognitions; cf. Jones \& McMahon, 1996). However, an alternative explanation for the finding that scores on the negative unipolar IAT appear unrelated to drinking behaviour is that the negative unipolar IAT was not a valid measure of implicit attitudes toward alcohol. As indicated above, the negative unipolar IAT could, for instance, reflect implicit attitudes toward the soft drinks contrast (i.e., less negative implicit attitudes toward soft drinks than toward alcohol). The present study, thus, aimed to clarify this issue by using non-relative unipolar ST-IATs rather than relative unipolar IATs.

Further, it is also possible that scores on the negative unipolar IAT reflect extrapersonal implicit attitudes (e.g., culturally shared associative knowledge) with respect to drinking alcohol that is not relevant to actual drinking behaviour (e.g., Karpinski \& Hilton, 2001; Olson \& Fazio, 2004). The influence of extrapersonal implicit attitudes on IAT scores might be greatly enhanced by using general target categories, such as alcohol, that are not specific enough given the behaviour that needs to be explained. Similar arguments have been raised by Fadardi, Cox, and Klinger (2006), who pointed out an IAT that presents standard target stimuli may be unable to measure behaviour-relevant implicit attitudes, since standard stimuli probably differ in the degree to which they are both known and liked across participants. To further examine this issue of specificity of the target categories, participants were divided into two conditions: Participants either performed the ST-IAT with alcohol or beer as the target category. Because only participants who regularly drank beer were included in this study, it was expected that the beer ST-IAT would be less contaminated by extrapersonal implicit attitudes and would, thus, assess behaviour-relevant implicit attitudes to a larger extent than the alcohol ST-IAT. Specifically, we expected a stronger relationship between ST-IAT scores and actual drinking behaviour in the beer condition than in the alcohol condition. Finally, we also measured explicit alcohol-related and beerrelated cognitions (depending on the condition), to examine whether the relationship between implicit attitudes and explicit cognitions would also differ depending on whether these measures were focused on alcohol or beer.

\section{Method}

\section{Participants}

A total of 48 students from Maastricht University ( 24 male, 24 female who were evenly divided over the alcohol and beer conditions; mean age = 20.25 years, $S D=2.23$ ) participated in the study in return for course credit or $€ 10$ in the form of a gift voucher. Only participants who drank beer on a regular basis were included. Participants on average consumed 16.27 $(S D=10.91)$ European standard alcoholic drinks per week. In the week prior to their participation, participants on average consumed $16.67(S D=13.09)$ alcoholic drinks, including $12.71(S D=12.59)$ beer consumptions and $3.96(S D=4.44)$ consumptions of other alcoholic drinks. On the 18 -item version of the Rutgers Alcohol Problem Index (RAPI; White \& Labouvie, 2000), participants had an average item score of $0.46(S D=0.27)$, while the average item score in clinical samples is about 0.80 (White \& Labouvie, 1989). On the Alcohol Use Disorder Identification Test (AUDIT; Saunders, Aasland, Babor, De la Fuente, \& Grant, 1993), participants' mean score was $10.04(S D=3.25)$ which is comparable with American college students (Fleming, Barry, \& MacDonald, 1991).

\section{Materials and Measures}

\section{Alcohol use and alcohol-related problems} Alcohol use was measured through a self-report questionnaire (Wiers, Hoogeveen, Sergeant \& Gunning, 1997) based on the timeline followback method (Sobell \& Sobell, 1990). Participants were asked to indicate how many drinks of different types of alcoholic beverages they consumed during each day of the past week, and for each day of the week, how many drinks they typically consumed on this day of the week. 
Alcohol-related problems were assessed with the RAPI and with the AUDIT. The RAPI described 18 alcohol-related problems or situations for which participants indicated how often they experienced these situations on a five-point Likert scale $(0=$ never, $4=$ very often $)($ Cronbach $\alpha=$ o.62). The AUDIT consisted of ten questions in a multiple choice format. The first three questions were related to alcohol use, the other seven to alcohol-related problems $(\alpha=0.61)$.

\section{Single-Target Implicit Association Test}

Participants performed a positive and a negative ST-IAT with either alcohol or beer as the target category. In the alcohol ST-IATs, the target category consisted of six alcoholic drinks (label 'alcohol'), while in the beer ST-IATs, the target category consisted of six different kinds of beer (label 'beer'). The exemplars of the (Dutch) alcohol category and the (Dutch) beer category were matched on familiarity $(M=4.40, S D=0.81$, and $M=4.10, S D=0.98$, respectively), valence $(M=$ $4.57, S D=0.61$, and $M=4.38, S D=0.89$, respectively), arousal $(M=4.22, S D=0.87$, and $M=4.35$, $S D=1.01$, respectively), and number of syllables. In the positive and negative ST-IAT versions, a positive attribute category (label 'pleasant') and a negative attribute category (label 'unpleasant') were presented, respectively, that were paired with two neutral attribute categories (label 'neutral') in balanced order. The positive and negative categories consisted of general positive and negative nouns (cf. Greenwald et al., 1998; Houben \& Wiers, 2006; Jajodia \& Earleywine, 2003). The exemplars of the positive and negative category were respectively evaluated as positive $(M=6.24, S D=0.58)$ and negative $(M=1.52$, $S D=0.44)$, while the exemplars of the two neutral categories were evaluated as neutral $(M=$ $3.94, S D=0.21$ and $M=3.99, S D=0.18$ ). The exemplars of the (Dutch) positive and negative attribute categories, and the exemplars of the two paired neutral categories were matched on familiarity $(M=4.87, S D=0.82, M=4.39, S D=0.93$, $M=3.92, S D=0.89$, and $M=4.17, S D=0.95$, respectively), arousal (neutral with respect to arousal; $M=4.47, S D=0.85, M=4.13, S D=0.68$, $M=3.90, S D=0.52$, and $M=3.86, S D=0.63$, respectively) and number of syllables ${ }^{1}$. All stimuli are listed in the Appendix.

The ST-IATs were programmed in ERTS 3.18 (Beringer, 1996) modelled after the ST-IAT by Wigboldus et al. (2004). All ST-IAT versions consisted of four blocks. Participants first practised the attribute discrimination (e.g., positive vs. neutral) with a right and a left response key. All attribute stimuli were presented twice, resulting in 24 trials. The second block was the first combination block which consisted of 48 trials. During this combination block both target and attribute stimuli were presented with the target category and the positive or negative attribute category (e.g., positive + alcohol/beer vs. neutral) assigned to the same response key (i.e., compatible re- sponse assignment). To keep the number of right and left responses equal, stimuli of the two categories that shared a response were presented twice, while stimuli of the unpaired neutral category were presented four times. Next, participants received 24 trials during which they practised the reversed attribute discrimination (e.g., neutral vs. positive), followed by the reversed combination block (e.g., neutral + alcohol/beer vs. positive; i.e., incompatible response assignment). Again, this combination block consisted of 48 trials because stimuli of the paired categories were presented twice while stimuli of the unpaired category were presented four times. Blocks 1 to 4 were then repeated for the other attribute dimension (e.g., negative vs. neutral). Target and attribute stimuli were presented in the middle of the computer screen, in black against a grey background. Instructions were presented before each task. During the task, the labels of the categories assigned to the left and right response key were presented in the corresponding upper corner of the computer screen. Stimuli remained on screen until a response was given. The inter-trial interval was $250 \mathrm{~ms}$. Feedback was presented in red beneath the stimuli after an incorrect response ('wrong'), and when responses were too fast ( $<300 \mathrm{~ms}$; 'too fast') or too slow (>300o ms; 'too slow').

\section{Explicit expectancies and attitudes}

Explicit expectancies with respect to beer or alcohol were assessed with an expectancy questionnaire that consisted of six positive expectancy items (alcohol: $\alpha=0.90$; beer: $\alpha=0.83$ ) and six negative expectancy items (alcohol: $\alpha=0.94$; beer: $\alpha=0.87)$. Each item asked participants to indicate on a Visual Analogue Scale (VAS) how

\footnotetext{
1 The choice of the exemplars that were used to represent the categories in the ST-IATs was based on ratings that were collected during a pilot study prior to the present study with 68 participants. Based on this pilot study, the exemplars of the (Dutch) alcohol category and the (Dutch) beer category were chosen in such a way that they were matched on familiarity $(\mathrm{M}=4.39, \mathrm{SD}=0.87$, and $\mathrm{M}=3.97, \mathrm{SD}=0.98$, respectively), valence $(\mathrm{M}=4.20, \mathrm{SD}=0.80$, and $\mathrm{M}=4.22, \mathrm{SD}=0.87$, respectively), arousal $(\mathrm{M}=4.21, \mathrm{SD}=0.89$, and $\mathrm{M}=4.31, \mathrm{SD}=$ 1.21, respectively), and number of syllables. Similarly, the exemplars of the positive and negative category were respectively evaluated as positive $(\mathrm{M}=6.16, \mathrm{SD}=0.62)$ and negative $(\mathrm{M}=1.77, \mathrm{SD}=0.54)$ in this pilot study, while the exemplars of the two neutral categories were evaluated as neutral $(\mathrm{M}=4.06, \mathrm{SD}=0.39$ and $\mathrm{M}=4.11, \mathrm{SD}=0.30)$. Based on the rating collected during the pilot study, the exemplars for the (Dutch) positive and negative attribute categories, and for the two paired neutral categories were also chosen so that they were matched on familiarity $(\mathrm{M}=5.43, \mathrm{SD}=0.90, \mathrm{M}=4.23$, $\mathrm{SD}=0.90, \mathrm{M}=4.07, \mathrm{SD}=0.85$, and $\mathrm{M}=4.36, \mathrm{SD}=0.98$, respectively), arousal (neutral with respect to arousal; $\mathrm{M}=$ 4.76, $\mathrm{SD}=0.67, \mathrm{M}=3.94, \mathrm{SD}=0.071, \mathrm{M}=4.29, \mathrm{SD}=0.59$, and $\mathrm{M}=4.07, \mathrm{SD}=0.56$, respectively) and number of syllables.
} 
much they agreed or disagreed with the following statement: 'After drinking alcohol (beer), I feel .... This statement was completed with the words pleasant, happy, sociable, friendly, enjoyable, and likable for the positive expectancy items and with the words unhappy, depressive, sad, lonely, moody, and down for the negative expectancy items. Explicit attitudes toward alcohol or beer were assessed with an attitude questionnaire and a feeling thermometer. The attitude questionnaire consisted of four semantic differentials which asked participants to indicate on a VAS how much they considered drinking alcohol (beer) to be unpleasant-pleasant, bad-good, boring-fun, and stupid-smart. The first and third item represented an affective attitude component (alcohol: $\alpha=0.81$; beer: $\alpha=$ o.92), the other two items represented a cognitive attitude component (alcohol: $\alpha=0.58$; beer: $\alpha=0.80$ ). The feeling thermometer was labelled in 10-degree increments ranging from o (very cold) to 100 (very warm). Participants were asked to indicate on the feeling thermometer how favourable they felt toward alcohol (beer).

\section{Procedure}

After filling out an informed consent form, participants were randomly assigned to either the alcohol condition or beer condition. Depending on the condition they were assigned to, participants performed the positive and negative alcohol ST-IAT or the positive and negative beer STIAT. The order of the positive and the negative St-IAT was counterbalanced across participants. Further, the assignment of the target category to the left or right response button was balanced across participants and remained constant for both the positive and negative ST-IAT. Also, the response assignment of the attribute categories to the left and right response key was counterbalanced so that half the participants performed the compatible combination task (i.e., positive or negative + alcohol or beer vs. neutral) before the incompatible combination task (i.e., neutral + alcohol or beer vs. positive or negative) in both the positive and negative ST-IAT. This order was reversed for the other half of the participants. After performing the positive and negative STIAT, participants received the feeling thermometer, the attitude questionnaire and the expectancy questionnaire. These questionnaires referred to either alcohol or beer, depending on the condition that participants were assigned to. Finally, all participants received the alcohol use questionnaire, the AUDIT and the RAPI, and were asked to judge all ST-IAT stimuli on familiarity, valence and arousal.

\section{Results}

Single-Target Implicit Association Test

ST-IAT effects were calculated with the D6oo scoring algorithm (Greenwald, Nosek, \& Banaji, 2003). Following the formula presented by Greenwald et al., practice blocks were included, error penalties (6oo ms) were given, and results were standardised at the level of the participant. For the positive ST-IAT, the D6oo measure was calculated so that higher scores indicate faster performance when alcohol or beer, depending on the condition, were paired with positive attributes, than when alcohol or beer shared a response with neutral attributes. Similarly, higher negative ST-IAT scores indicate faster performance when alcohol or beer, depending on the condition, were paired with negative attributes, than when alcohol or beer were paired with neutral attributes. Preparatory analyses revealed no influential outliers on ST-IAT data.

Internal consistencies were calculated for each ST-IAT by correlating the D6oo measure calculated for the practice trials (i.e., IAT effect based on the first half of the compatible combination trials and the first half of the incompatible combination trials) with the IAT effect measure calculated for the test trials (i.e., IAT based on the second half of the compatible and incompatible combination trials) (as in Greenwald et al., 2003). However, dividing a measure into halves underestimates the reliability of the entire measure, and therefore we also calculated correlations adjusted with the Spearman-Brown correction which compensates for this underestimation of the true internal consistency (cf. Karpinski \& Steinman, 2006). Internal consistencies for the positive and negative alcohol ST-IAT were 0.77 and 0.29 , respectively. For the positive and negative beer ST-IAT, the respective internal consistencies were 0.29 and 0.45 .

With respect to scores on the positive ST-IAT, there was no significant difference between the alcohol condition and the beer condition, $t(46)=$ $0.29, p=0.773$. In both the alcohol and beer condition, ST-IAT performance was significantly faster when alcohol or beer were paired with the positive attribute category than when alcohol or beer were paired with a neutral attribute category, $t(23)=4.57, p<0.001$, and $t(23)=5.34, p<$ 0.001 , respectively. Results also showed no significant difference between the alcohol condition and the beer condition on the negative STIAT, $t(46)=0.45, p=0.653$. Participants were significantly faster in both the alcohol ST-IAT and in the beer ST-IAT when alcohol or beer shared a response with the negative attribute category than when alcohol or beer were paired with a neutral attribute category, $t(23)=5.87, p<0.001$, and $t(23)=4.84, p<0.001$, respectively. Mean response latencies as a function of target are 


\begin{tabular}{|c|c|c|c|c|}
\hline \multirow[t]{3}{*}{ Table 1} & \multicolumn{4}{|c|}{$\begin{array}{l}\text { Mean response latencies (with standard deviations between parentheses) for the compatible } \\
\text { and incompatible response assignments in both the positive and negative ST-IAT as a function } \\
\text { of target category. }\end{array}$} \\
\hline & \multicolumn{2}{|c|}{ Positive ST-IAT } & \multicolumn{2}{|c|}{ Negative ST-IAT } \\
\hline & Compatible & Incompatible & Compatible & Incompatible \\
\hline Alcohol & $633.85(103.09)$ & 766.89 (173.88) & $631.71(86.48)$ & 754.59 (149.69) \\
\hline Beer & $652.38(163.90)$ & 703.68 (152.30) & $658.19(133.98)$ & $736.93(140.31)$ \\
\hline
\end{tabular}

In the positive ST-IAT, alcohol/beer was paired with a positive attribute category during the compatible combination and with a neutral attribute category during the incompatible combination. In the negative ST-IAT, alcohol/beer was paired with a negative attribute category during the compatible combination and with a neutral attribute category during the incompatible combination.

shown in Table 1 , separately for the positive and negative ST-IAT versions ${ }^{2}$.

\section{Explicit expectancies and attitudes}

One participant did not fill out the questionnaires with respect to alcohol-related expectancies and attitudes, so this participant was excluded from the analyses with respect to explicit expectancies and attitudes. For the remaining 47 participants, mean scores were calculated separately for positive and negative expectancy items of the expectancy questionnaire as well as for the affective and cognitive attitude component of the attitude questionnaire. Results showed no difference in mean positive expectancy scores between the alcohol condition $(M=76.56, S D=$ 13.49) and the beer condition $(M=73.28, S D=$ 13.66), $t(45)=0.83, p=0.412$. Also, there was no difference between the alcohol and beer condition with respect mean negative expectancy scores $(M=18.65, S D=13.81$, and $M=17.85, S D=$ 15.20 , respectively), $t(45)=0.19, p=0.851$. Hence, these results indicate that participants to the same extent expected positive effects but not negative effects from drinking alcohol and from drinking beer. Further, results showed no difference between mean alcohol-related affective attitude scores $(M=86.06, S D=11.76)$ and mean beer-related affective attitude scores $(M=79.33$, $S D=22.98), t(45)=1.27, p=0.210$, nor between

2 When we subjected the D6oo measure to a 2 (Valence: positive or negative) $x_{2}$ (Target: beer or alcohol) $x_{2}$ (Order: negative ST-IAT first or positive ST-IAT first) ANOVA with repeated measures on the first factor, results showed no significant main effects or interaction effects ( $\mathrm{p}>0.45)$. However, for reasons of clarity and interpretability, we report IAT effects as a function of target (alcohol or beer) and valence (positive ST-IAT or negative ST-IAT). mean alcohol-related cognitive attitude scores $(M=47.00, S D=14.48)$ and mean beer-related cognitive attitude scores $(M=47.11, S D=19.38)$, $t(45)=-0.02, p=0.983$. Finally, results with the feeling thermometer showed that feelings toward alcohol $(M=72.08, S D=10.21)$ were equally favourable to feelings toward beer $(M=65.00, S D$ $=17.97), t(45)=1.67, p=0.102$.

We then examined the relationship of ST-IAT scores with explicit expectancies and attitudes separately for the alcohol condition (Table 2) and the beer condition (Table 3 ). In the alcohol condition, ST-IAT scores in the positive dimension were positively correlated with scores on the cognitive attitude scores, indicating that participants with stronger positive implicit attitudes toward alcohol also considered drinking alcohol to be more sensible. Further, positive alcoholrelated expectancies, the affective attitude component and the feeling thermometer were positively correlated with each other and negatively correlated with negative alcohol-related expectancies. None of the other correlations in the alcohol condition reached conventional levels of significance. In the beer condition, the ST-IAT was uncorrelated with explicit beer-related expectancies and attitudes. Further, positive beerrelated expectancies, the affective attitude component and the feeling thermometer were positively correlated with each other but not with negative beer-related expectancies. Moreover, the cognitive attitude component correlated positively with both the affective attitude component and the feeling thermometer, indicating that participants with more favourable attitudes toward beer also considered drinking beer to be sensible. None of the other correlations in the beer condition reached conventional levels of significance. 


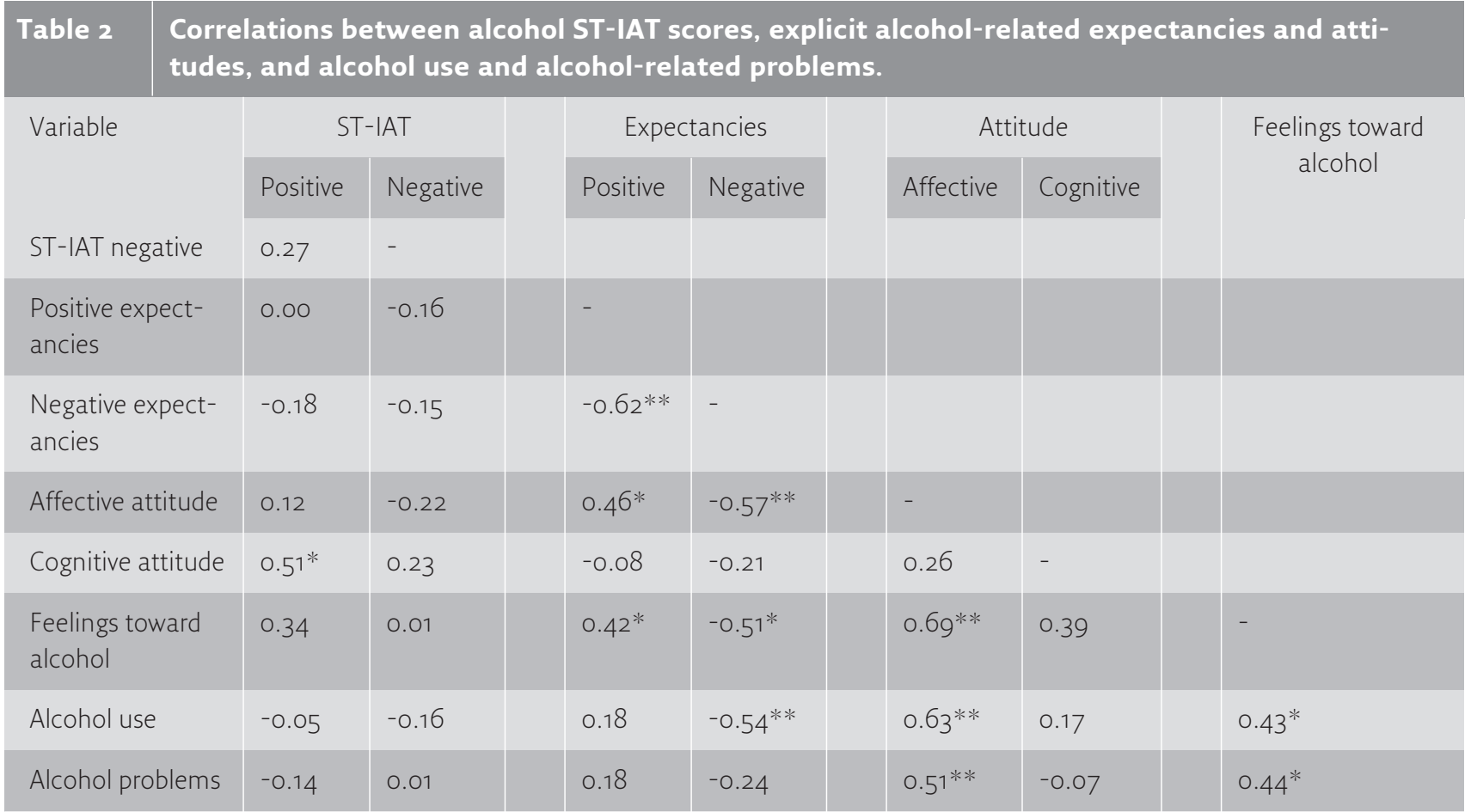

** Correlation is significant at the 0.01 level (two-tailed), * Correlation is significant at the 0.05 level (two-tailed).

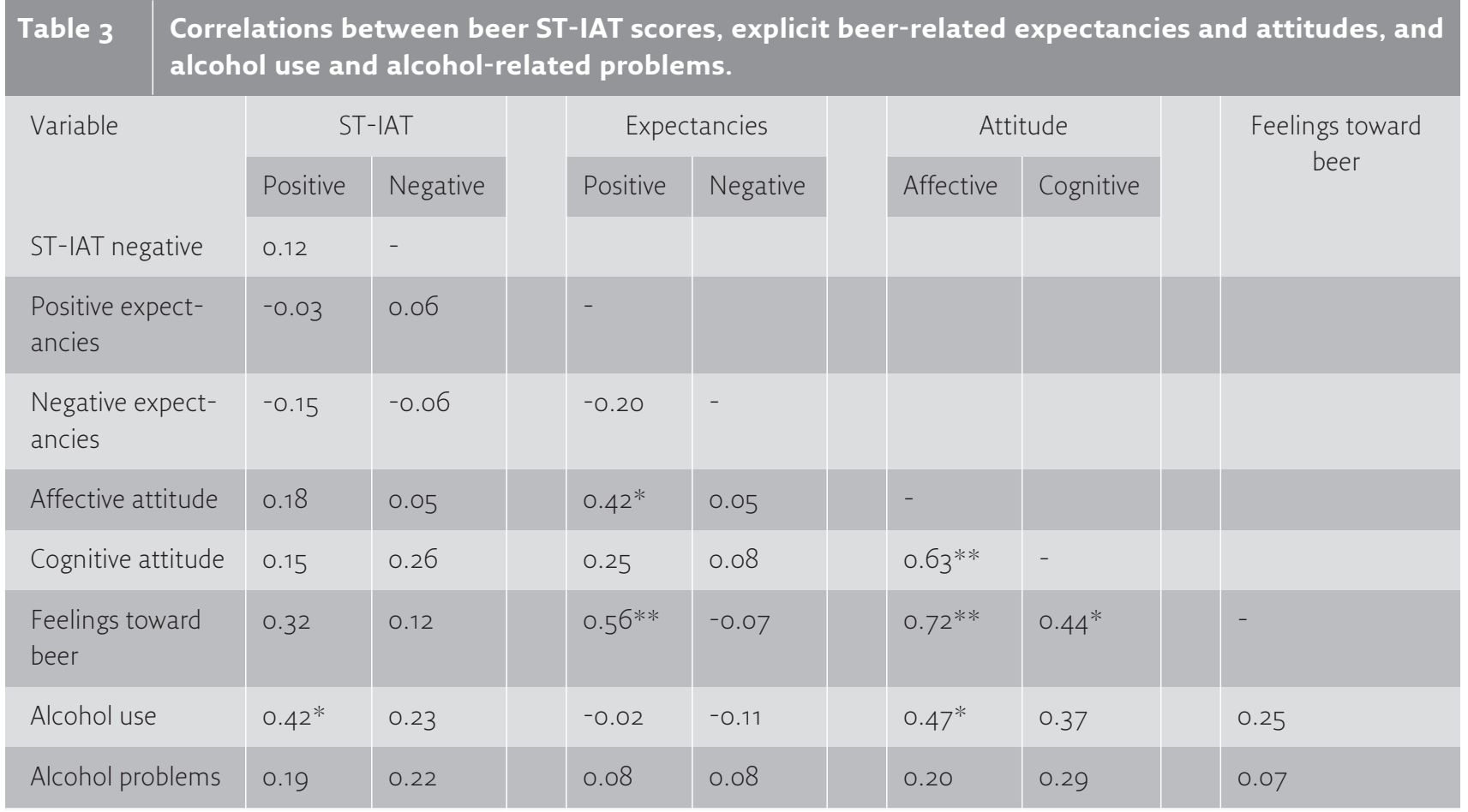

** Correlation is significant at the 0.01 level (two-tailed), * Correlation is significant at the 0.05 level (two-tailed). 


\section{Alcohol use and alcohol-related problems}

Alcohol consumption during the past week and average weekly alcohol consumption were estimated from the alcohol use questionnaire. An estimate of alcohol use was then calculated as the mean of average alcohol consumption during the past week and average weekly alcohol consumption. Further, average alcohol use during the past week and average alcohol use were first log-transformed in order to obtain a normal distribution for the alcohol use estimate. An estimate of alcohol-related problems was computed as the mean of the z-transformed RAPI and AUDIT sum scores. The alcohol use estimate and the alcohol-related problems estimate were significantly correlated, $r=0.63, p<0.001$, indicating that participants with increased levels of alcohol consumption also experienced more alcohol-related problems.

Correlations of alcohol use and alcohol-related problems with ST-IAT scores and expectancies and attitudes were calculated separately for the alcohol condition (Table 2) and the beer condition (Table 3). In the alcohol condition, scores on the explicit measures, but not ST-IAT scores, were significantly related to alcohol use and alcohol-related problems. Specifically, participants who held stronger positive attitudes toward alcohol, as measured with both the affective attitude component and the feeling thermometer, consumed more alcohol and experienced more alcohol-related problems. In addition, participants who did not expect negative effects from drinking alcohol also consumed more alcohol. In the beer condition, in contrast, alcohol use was related to both explicit measures and to ST-IAT scores. With respect to scores on the ST-IAT, results showed that participants with stronger positive implicit attitudes toward beer also consumed more alcohol. Further, results indicated that participants with stronger positive attitudes toward beer, measured with the affective attitude component, consumed more alcohol.

\section{Discussion}

Previous studies using unipolar IATs suggest that implicit positive attitudes toward alcohol are related to drinking behaviour whereas implicit negative alcohol attitudes are not (e.g., Houben \& Wiers, 2006; Jajodia \& Earleywine, 2003; McCarthy \& Thompsen, 2006). In the present study, we measured single implicit attitudes toward alcohol with unipolar ST-IATs to examine to what extent previous findings were affected by the relative nature of unipolar IATs. Further, participants performed the ST-IAT with either alcohol or beer as the target category because it was expected that a beer ST-IAT would assess behaviour-relevant implicit attitudes to a greater extent than an alcohol ST-IAT since all participants were regular beer drinkers. Although the present findings did not show significant differences in the overall size of IAT effects or with respect to the relationship between implicit cognitions and explicit cognitions between the alcohol and beer condition, results did demonstrate that positive beer ST-IAT scores were related to alcohol use whereas positive alcohol ST-IAT scores were not. Negative alcohol and beer ST-IAT scores, however, were both unrelated to drinking behaviour.

First, results with the beer ST-IAT showed the same pattern of results as previously found with unipolar IATs: Positive implicit attitudes toward beer were related to drinking behaviour whereas negative implicit attitudes were unrelated to behaviour. Hence, the present results demonstrate that results with unipolar IATs were not due to the soft drinks contrast that was used in previous studies. Together, results with both unipolar IAT and unipolar ST-IAT variants indicate that implicit positive alcohol-related attitudes, but not implicit negative attitudes, are related to drinking behaviour (e.g., present study; Houben \& Wiers, 2006; Jajodia \& Earleywine, 2003; McCarthy \& Thompsen, 2006). Second and in contrast to the beer ST-IAT, the alcohol ST-IAT did not show a relationship to drinking behaviour. These findings are, thus, in line with the hypothesis that a beer ST-IAT would reflect implicit attitudes that are relevant to drinking behaviour to a greater extent than an alcohol ST-IAT, since all participants were regular beer drinkers. It is, however, important to note that previous studies did find a relationship between alcohol IATs and drinking behaviour (e.g., Houben \& Wiers, 2006; Jajodia \& Earleywine, 2003; McCarthy \& Thompsen, 2006). However, in contrast to this study, previous studies did not select only regular beer drinkers as participants. Hence, the present findings should not be seen as evidence against the validity of alcohol (ST-)IATs. Rather, these findings imply that, in the (ST-)IAT, target categories should be as specific as possible given the behaviour that needs to be explained. Thus, it might be important to customise IAT target categories in order to make sure that IAT scores reflect implicit attitudes that are both relevant and related to behaviour.

Related to this issue, Olson and Fazio (2004) demonstrated that a personalised IAT that eliminates all reference to normative information from the attribute categories better reflects implicit attitudes that predict behaviour than a standard IAT. Houben \& Wiers (2007a) also showed that such a personalised IAT yields stronger positive implicit attitudes toward alcohol than negative implicit attitudes that were strongly related to alcohol use. However, this personalised IAT as developed by Olson and Fazio (2004) only personalises attribute categories, and not target categories as was done in this 
study. As indicated above, the present results indicate that it might be equally or even more important to also tailor or personalise the target categories (cf. Fadardi et al., 2006). In this respect, it should be noted that Houben and Wiers $(2007 \mathrm{~b})$ used a personalised IAT that not only presented personalised attribute categories, but also used participants' own liked and disliked alcoholic drinks and soft drinks as target stimuli. In contrast to what was expected, however, Houben and Wiers (2007b) were unable to show superior predictive validity for their personalised IAT compared with a standard alcohol versus soft drinks IAT. Still, it should be noted that Houben and Wiers $(2007 \mathrm{~b})$ counterbalanced the order of the personalised IAT and the standard IAT and included mainly light drinking participants. Thus, future research should further examine the value of personalising IAT categories as well as individual category exemplars as a means of increasing the IATs predictive validity.

Further, it is important to note that even though a myriad of research has been devoted to the IAT, showing that it can offer both a reliable and valid measure of implicit attitudes (e.g., Hofmann, Gawronski, Gschwendner, Le, \& Schmitt, 2005; Nosek, Greenwald, \& Banaji, 2006), uncertainty remains as to what the IAT exactly measures. Specifically, it was suggested that IAT effects do not necessarily reflect implicit attitudes but that they can also be influenced by recoding processes (De Houwer, 2003a; Rothermund, Wentura, \& De Houwer, 2005; for evidence see, e.g., De Houwer, Geldof, \& De Bruycker, 2005; Mierke \& Klauer, 2003; Rothermund \& Wentura, 2004). Recoding means that target and/or attribute stimuli are categorised based on features such as familiarity, valence, and salience, that do not match the 'nominal definitions' of the target (e.g., alcohol vs. soft drinks) and/or attribute categories (e.g., positive vs. negative; cf. Greenwald, Nosek, Banaji, \& Klauer, 2005). As a result, it is difficult to interpret the meaning of IAT effects because it is unclear with regard to which feature the target and attribute categories are compatible. To overcome this problem of the IAT, Rothermund and colleagues recently introduced a modified version of the IAT, which they termed IAT-RF (short for 'Recoding-Free IAT'; Rothermund, Teige-Mocigemba, Gast, \& Wentura, 2009). Basically, the IAT-RF aims to eliminate effects of recoding by abandoning the block structure of the IAT. In the IAT-RF, compatible and incompatible combinations of the categories vary randomly between trials within a single block. This random switching of response assignments undermines any type of recoding, because efficient recoding requires a consistent mapping of categories onto responses. Houben, Rothermund, and Wiers (in press) recently demonstrated that the alcohol-IAT may partly reflect recoding processes and that eliminating these recoding influences, for instance by using the IAT-RF, may provide a better measure of implicit alcohol associations.

Clearly, recoding processes are not only a problem for the standard bipolar IAT, but also for unipolar IAT and ST-IAT variants. While Houben and Wiers (2006) showed that recoding in terms of salience could not account for their results with unipolar IAT variants, it remains unclear to what extent recoding processes may have influenced the present findings with the unipolar ST-IAT. Since the unipolar ST-IAT presents only one target category in combination with a unipolar attribute dimension, the unipolar ST-IAT is probably much easier to perform than the unipolar IAT, which presents two target categories in combination with the attribute dimension. Importantly, due its simplicity, the unipolar ST-IAT may invite recoding processes to a greater extent than the bipolar IAT and the unipolar IAT. In the present study, the negative ST-IAT variants were unrelated to alcohol consumption and may, thus, reflect recoding processes rather than implicit alcohol or beer attitudes. However, given that the positive unipolar beer ST-IAT was related to drinking behaviour, it is unlikely that the positive unipolar ST-IAT solely reflects recoding processes. The positive alcohol ST-IAT, on the other hand, was unrelated to drinking behaviour, which could suggest that this ST-IAT variant was influenced by recoding processes. However, given that both the positive beer ST-IAT and the positive alcohol ST-IAT presented the same attribute dimension in combination with only one target category, it could be argued that both ST-IAT variants should have been affected by recoding processes to the same extent. Hence, recoding processes cannot readily explain the present differences between the positive alcohol ST-IAT and the positive beer ST-IAT with respect to their relationship with drinking behaviour. Nevertheless, given the potential value of the unipolar IATs and unipolar ST-IATs for assessing compatibilities for concepts for which ambivalence is likely to be high, future research needs to establish how recoding influences unipolar IAT and ST-IAT variants and whether they can be adapted to be free from recoding effects as was successfully accomplished for the bipolar IAT (e.g., Houben et al., in press).

Finally, there are some limitations to the present findings that should be noted. First, due to the small number of participants in this study, we were unable to examine the incremental validity of the alcohol and beer ST-IAT. While previous studies have demonstrated that positive unipolar IATs predict variance in drinking behaviour above explicit alcohol-related cognitions (e.g., Houben \& Wiers, 2006; Jajodia \& Earleywine, 2003), our sample did not allow similar analyses. Thus, future research needs to examine whether unipolar ST-IATs also show incremen- 
tal validity. Further, the ST-IAT variants used in this study showed large variability with respect to their internal consistency. While the positive alcohol ST-IAT showed a relatively high internal consistency, the internal consistencies for the other three ST-IAT variants were much lower. One possible reason for these low internal consistencies could be that the response assignment of the attribute categories was switched during the compatible and incompatible combination blocks of the ST-IAT, while typically the response assignment of the targets is switched. However, this procedure was similar to that of studies using unipolar IAT versions (Houben \& Wiers, 2006; Jajodia \& Earleywine, 2003; McCarthy \& Thompsen, 2006). Alternatively, it is possible that unipolar (ST-)IAT variants simply do not reach the same level of internal consistency as has been found for bipolar (ST-)IAT variants (cf. Greenwald et al., 2003; Karpinski \& Steinman, 2006). At this time, it is difficult to state strong conclusions regarding this issue, and future research should investigate whether internal consistencies are indeed lower for unipolar (ST-)IAT versions as compared with bipolar (ST)IAT versions.

In conclusion, using unipolar ST-IAT versions, the present study demonstrates that positive implicit alcohol-related attitudes are related drinking behaviour while negative implicit alcohol-related attitudes are not. Thus, the present findings replicate and extend previous work using unipolar IAT versions, by demonstrating that previous findings were not caused by the contrast soft drinks. Moreover, this pattern of results was only demonstrated in the present sample of regular beer drinkers when a specific beer target category was used in the STIAT, but not when a more general alcohol target category was presented. Thus, these results indicate that it is useful to fine-tune target categories in the (ST-)IAT to the behaviour that needs to be explained in order to assess behaviour-relevant implicit attitudes rather than extrapersonal implicit attitudes that are irrelevant for behaviour.

\section{Author notes}

Both authors are funded by 'VIDI' grant 452.02.005 from the Dutch National Science Foundation (NWO) awarded to the second author.

\section{References}

Beringer, J. (1996). Experimental Run Time System (ERTS), Version 3.18. Frankfurt, Germany: BeriSoft.

Conner, M., \& Sparks, P. (2002). Ambivalence and Attitudes. European Review of Social Psychology, 12, 37-70.

De Houwer, J. (2002). The implicit association test as a tool for studying dysfunctional associations in psychopathology: Strengths and limitations. Behavior Therapy and Experimental Psychiatry, 53, 115133.

De Houwer, J. (2003a). A structural analysis of indirect measures of attitudes. In J. Musch \& K. C. Klauer (Eds.), The psychology of evaluation: Affective processes in cognition and emotion (pp. 219-244). Mahway, NJ: Erlbaum.

De Houwer, J. (2003b). The Extrinsic Affective Simon Task. Experimental Psychology, 50, 77-85. De Houwer, J., Crombez, G., Koster, E. H. W., \& De Beul, N. (2004). Implicit alcohol-related cognitions in a clinical sample of heavy drinkers. Journal of Behavior Therapy and Experimental Psychiatry, 35, 275-286.

De Houwer, J., Geldof, T., \& De Bruycker, E. (2005). The Implicit Association Test as a general measure of similarity. Canadian Journal of Experimental Psychology, 59, 228-239.

de Jong, P. J., Wiers, R. W., van de Braak, M., \& Huijding, J. (2007). Using the Extrinsic Affective
Simon Test as a measure of implicit attitudes toward alcohol: Relationship with drinking behavior and alcohol problems. Addictive Behaviors, 32, 881-887.

Fadardi, J. S., Cox, W. M., \& Klinger, E. (2006). Individualized versus general measures of implicit cognition. In R. W. Wiers \& A. W. Stacy (Eds.), Handbook of Implicit Cognition and Addiction (pp. 121133). Thousand Oaks, CA: SAGE Publishers.

Fleming, M. F., Barry, K. L., \& MacDonald, R. (1991). The alcohol use disorders identification test (AUDIT) in a college sample. The International Journal of the Addictions, 26, 1173-1185.

Gawronski, B., Hofmann, W., \& Wilbur, C. J. (2006). Are "implicit" attitudes unconscious? Consciousness and Cognition, 15, 485-499.

Greenwald, A. G., McGhee, D. E., \& Schwartz, J. L. K. (1998). Measuring individual differences in implicit cognition: The implicit association test. Journal of Personality and Social Psychology, 74, 14641480.

Greenwald, A. G., Nosek, B. A., \& Banaji, M. R. (2003). Understanding and using the implicit association test: 1 . An improved scoring algorithm. Journal of Personality and Social Psychology, 85, 197-216.

Greenwald, A. G., Nosek, B. A., Banaji, M. R., \& Klauer, K. C. (2005). Validity of the salience asymmetry interpretation of the IAT: Comment on 
Rothermund and Wentura (2004). Journal of Experimental Psychology: General, 134, 420-425.

Hofmann, W., Gawronski, B., Gschwendner, T., Le, H., \& Schmitt, M. (2005). A meta-analysis on the correlation between the implicit association test and explicit self-report measures. Personality and Social Psychology Bulletin, 31, 1369-1385.

Houben, K., Rothermund, K., \& Wiers, R. W. (in press). Eliminating recoding in the Alcohol-IAT: An application of the IAT-RF. Addictive Behaviors. Houben, K., \& Wiers, R. W. (2006). Assessing Implicit Alcohol Associations with the Implicit Association Test: Fact or Artifact? Addictive Behaviors, 31, 1346-1362.

Houben, K., \& Wiers, R. W. (2007a). Are drinkers implicitly positive about drinking alcohol? Personalizing the alcohol-IAT to reduce negative extrapersonal contamination. Alcohol and Alcoholism, 42, 301-307.

Houben, K., \& Wiers, R. W. (2007b). Personalizing the alcohol-IAT with individualized stimuli: Relationship with drinking behavior and drinkingrelated problems. Addictive Behaviors, 32, 28522864.

Jajodia, A., \& Earleywine, M. (2003). Measuring alcohol expectancies with the implicit association test. Psychology of Addictive Behaviors, 17, 126133.

Jones, B. T., \& McMahon, J. (1996). A comparison of positive and negative alcohol expectancy and value and their multiplicative composite as predictors of post-treatment abstinence survivorship. Addiction, 91, 89-99.

Karpinski, A., \& Hilton, J. L. (2001). Attitudes and the implicit association test. Journal of Personality and Social Psychology, 81, 774-788.

Karpinski, A., \& Steinman, R. B. (2006). The SingleCategory Implicit Association Test as a measure of implicit social cognition. Journal of Personality and Social Psychology, 91, 16-32.

McCarthy, D. M., \& Thompsen, D. M. (2006). Implicit and explicit measures of alcohol and smoking cognitions. Psychology of Addictive Behaviors, 20, 436-444.

Mierke, J., \& Klauer, K. C. (2003). Method-specific variance in the Implicit Association Test. Journal of Personality and Social Psychology, 85, 1180-1192.

Nosek, B. A., Greenwald, A. G., \& Banaji, M. R. (2006). The Implicit Association Test at age 7: A methodological and conceptual review. In J. A. Bargh (Ed.), Social psychology and the unconscious: The automaticity of higher mental processes. (pp. 265-292): Psychology Press.

Olson, M. A., \& Fazio, R. H. (2004). Reducing the influence of extra-personal associations on the implicit association test: Personalizing the IAT. Journal of Personality and Social Psychology, 86, 653667.
Rothermund, K., Teige-Mocigemba, S., Gast, A., \& Wentura, D. (2009). Minimizing the influence of recoding in the Implicit Association Test: The Recoding-Free implicit Association Test. The Quarterly Journal of Experimental Psychology, 62, 8498.

Rothermund, K., \& Wentura, D. (2004). Underlying processes in the Implicit Association Test (IAT): Dissociating salience from associations. Journal of Experimental Psychology: General, 133, 139-165.

Rothermund, K., Wentura, D., \& De Houwer, J. (2005). Validity of the salience asymmetry account of the IAT: Reply to Greenwald, Nosek, Banaji, and Klauer (2005). Journal of Experimental Psychology: General, 134, 426-430.

Saunders, J. B., Aasland, O. G., Babor, T. F., De la Fuente, J. R., \& Grant, M. (1993). Development of the Alcohol use Disorders Identification Test (AUDIT): WHO collaborative project on early detection of persons with harmful alcohol consumption. Addiction, 88, 791-804.

Sobell, L. C., \& Sobell, M. B. (1990). Self-report issues in alcohol abuse: State of the art and future directions. Behavioral Assessment, 12, 77-90.

White, H. R., \& Labouvie, E. W. (1989). Towards the assessment of adolescent problem drinking. Journal of Studies on Alcohol, 50, 30-37.

White, H. R., \& Labouvie, E. W. (2000). Longitudinal trends in problem drinking as measured by the Rutgers Alcohol Problem Index. Paper presented at the 23rd Annual Scientific Meeting of the Research Society on Alcoholism. Denver, CO. Wiers, R. W., Ganushchack, A., Van de Ende, N., Smulders, F. T. Y., \& de Jong, P. J. (2003). Comparing implicit alcohol associations across different rt-measures: The Implicit Association Test (IAT) versus varieties of the Extrinsic Affective Simon Task (EAST). Paper presented at the 15th Annual Convention of the American Psychological Association (APS). Atlanta, GA. May 29-June 1, 2003. Wiers, R. W., Hoogeveen, K.-J., Sergeant, J. A., \& Gunning, W. B. (1997). High- and low-dose alcohol-related expectancies and the differential associations with drinking in male and female adolescents and young adults. Addiction, 92, 871888.

Wiers, R. W., van de Luitgaarden, J., van den Wildenberg, E., \& Smulders, F. T. Y. (2005). Challenging implicit and explicit alcohol-related cognitions in young heavy drinkers. Addiction, 100, 806-819.

Wiers, R. W., Van Woerden, N., Smulders, F. T. Y., \& de Jong, P. J. (2002). Implicit and explicit alcoholrelated cognitions in heavy and light drinkers. Journal of Abnormal Psychology, 111, 648-658.

Wigboldus, D. H. J., Holland, R. W., \& van Knippenberg, A. (2004). Single target implicit associations. Unpublished Manuscript. 


\section{Appendix}

Target stimuli

Alcohol: wine, Bacardi, whisky, Heineken, Hoegaarden, Amstel (the last three are beer brands). Beer: Trappist, Pils, Jupiler, Heineken, Hoegaarden, Amstel

Attribute stimuli

Pleasant: love, sunshine, warmth, peace, hug, rainbow

Unpleasant: war, depression, pain, fight, disease, sorrow

Neutral 1: paper, circle, ballpoint, factory, truck, magnet

Neutral 2: letter, square, page, machine, scissors, window 